\title{
The pericardium of Oikopleura dioica (Tunicata, Appendicularia) contains two distinct cell types and is rotated by 90 degrees to the left
}

\author{
Mai-Lee Van Le ${ }^{1} \cdot$ Maria Novosolov² $\cdot$ Dorothee Huchon ${ }^{3} \cdot$ Thomas Stach $^{4}$ (D)
}

Received: 7 May 2021 / Revised: 20 August 2021 / Accepted: 26 August 2021 / Published online: 4 September 2021

(c) The Author(s) 2021

\begin{abstract}
The planktonic Oikopleura dioica belongs to Tunicata, the probable sister taxon to Craniota, and might show plesiomorphic characters, conserved from the common lineage of Tunicata and Craniota. In O. dioica a pericardium in a position similar to other chordates but also to the heart and pericardium of craniates is found. Surprisingly, little is known about the ultrastructure of the pericardium in $O$. dioica. Here, we show based on electron microscopy that the pericardium is completely lined by a single layer of 16 epithelial cells: 6 epithelial myocardial cells on the left side of the pericardium and 10 peritoneal cells constituting the right side. One of the peritoneal cells, situated at the ventral border between peritoneal cells and myocardial cells has an extension that anchors the pericardium to the basal lamina beneath the latero-ventral epidermis. The primary body cavity of $O$. dioica appears quite uniformly clear in electron microscopic aspect but several sheets, resembling the basal lamina of the pericardium cross the larger spaces of the body cavity and connect to the pericardial basal lamina. This is the first detailed description of two distinct cell types in the epithelial lining of the pericardium of $O$. dioica. In comparison with other chordates, we conclude that two cell types can be reconstructed for the last common ancestor of Chordata at least. The position of the pericardium at the intersection of trunk and tail in combination with the basal-lamina like sheets spanning the hemocoel is probably of importance for the function of the circulation of the hemocoelic fluid. Similar to the tail, the axis of the pericardium is shifted through 90 degrees to the left as compared to the main body axis of the trunk and we infer that this shift is an apomorphic character of Appendicularia.
\end{abstract}

Keywords Heart $\cdot$ Pericardium $\cdot$ Coelom $\cdot$ Larvacea $\cdot$ Urochordata

Thomas Stach

thomas.stach@hu-berlin.de

Mai-Lee Van Le

maileevanle@gmail.com

Maria Novosolov

marianovosolov@gmail.com

Dorothee Huchon

huchond@tauex.tau.ac.il

1 Institut für Biologie, Humboldt-Universität zu Berlin, Vergleichende Zoologie, Berlin, Germany

2 GeoGenetics Centre, Faculty of Health and Medical Sciences, The GLOBE Institute, University of Copenhagen, Copenhagen, Denmark

3 School of Zoology, George S. Wise Faculty of Life Sciences, Tel Aviv University, Aviv, Israel

4 Institut für Biologie, Humboldt-Universität zu Berlin, Vergleichende Elektronenmikroskopie, Berlin, Germany

\section{Introduction}

Oikopleura dioica Fol, 1872 is a planktonic chordate belonging to a small group of marine animals, the so-called appendicularians and it has recently been developed into a model organism for molecular biological studies (e.g., Bouquet et al. 2009; Glover 2020; Ferrández-Roldán et al. 2021). Besides utilizing an elaborate, extracorporal filtering device to feed, having an extremely short generation span of merely 5 days, $O$. dioica attracted the interest of researchers because of its phylogenetic position. It belongs to Tunicata, the probable sister taxon to Craniota (sensu Lambertz 2016), the vertebrates (see e.g., Delsuc et al. 2006, 2018; Kocot et al. 2018), and within Tunicata, Appendicularia is considered to be the sister taxon to all remaining tunicates (see e.g., Delsuc et al. 2006, 2018; Kocot et al. 2018; Braun et al. 2020). This phylogenetic position attracts interest, because in comparative studies with other tunicates, vertebrates, and cephalochordates, $O$. dioica might show plesiomorphic 
characters that have been conserved from the common lineage of Tunicata and Craniota.

Oikopleura dioica is by far the best studied species of the approximately 69 appendicularian species and many morphological details such as the fine anatomy of the nervous system and the sensory organs (e.g., Holmberg 1984, 1986; Olsson et al 1990; Canestro et al. 2005), the ultrastructure of the epidermis (Burighel et al 1989; Nakashima et al. 2011), the digestive tract (Burighel et al. 2001), the morphogenetic patterning of the oikoplastic epithelium (Kishi et al. 2017), or the detailed cell lineage (Stach et al. 2008) are only known in this appendicularian model species. Recently, Nishida et al. (2021) have complimented the earlier studies with a detailed morphological description of a hatchling and a juvenile of $O$. dioica based on serial block face scanning electron microscopy (SBF-SEM), a technique that allows for the three-dimensional visualization of anatomical features at near ultrastructural level.

In the ventral part of the trunk of appendicularians, immediately posterior to the pharynx is a pulsating coelomic compartment that was discovered by Lankester (1874) in Fritillaria pellucida (Busch 1851) (Lankester used the junior synonym Appendicularia furcata). This is the comparable position not only of the pericard/heart complex in ascidians (e.g., Hoshino 1969; Davidson 2007; Evans and Christiaen 2016; Konrad 2016), but also of a major blood vessel in cephalochordates (also known as lancelets) associated with a coelomic compartment (e.g., Rähr 1979; Stach 2000), and of the heart and pericardium in vertebrate fishes (e.g., Farrell 2007; Kokubo et al. 2010; Ghadam et al. 2016). Compared to the ascidians, the pericard/heart complex in $O$. dioica is a genuinely simple structure, constituting a small coelomic sac. Surprisingly, very little is known about the ultrastructure of the pericardium in $O$. dioica. Stach (2009) investigated the general anatomy of the mesoderm in tunicates and concerning the pericardium of $O$. dioica only briefly mentions that "the internal lumen ... is completely lined by flat mesodermal cells" (p. 101) and that "the major part of their cytoplasm is occupied by myofilaments" (p. 102). Nishida et al. (2021) reconstruct the three-dimensional anatomy of the pericardium of a juvenile. These authors were able to determine the number of nuclei, and thus the number of cells that make up the pericardium. They also confirmed a difference between the thickness of the right and left sides of the pericardium that had been noticed by Onuma et al. (2017) before. Nishida et al. (2021) concluded that the left side consisted of six long muscle cells (here termed myocardial cells), whereas the right side was built by ten pericardial epithelium cells (here termed peritoneal pericardial cells). The authors state that with the SBF-SEM method they used "it was difficult to recognize muscle fibers in the SBF-SEM images." At the same time, Savelieva and Temereva (2020) have recently described the ultrastructure of two different cell types, myoepithelial cells and peritoneal cells, in the pericardium of another appendicularian species Oikopleura gracilis Lohmann 1896. Thus, it seems convincing to expect two different cell types to be present in the pericardium of $O$. dioica as well, but this has not been demonstrated so far and the detailed ultrastructure of these cells remains to be investigated. In order to fill this gap in our knowledge, we examine the subcellular anatomy of the pericardial cells of the phylogenetically important model organism $O$. dioica.

\section{Materials and methods}

We analyzed three specimens of Oikopleura dioica: two were prepared in the Laboratory for Comparative Electron Microscopy at Humboldt-University, Berlin.

The two specimens, used for investigating cellular ultrastructure were prepared as follows:

Living specimens of $O$. dioica were provided from Sars International Centre for Marine Molecular Biology (SICMMB) and cultured at Humboldt-University zu Berlin (HU) through numerous generations following culturing methods detailed in Bouquet et al. (2009).

Individual juvenile animals (day 3-4) were immersed for $1 \mathrm{~h}$ in a cold solution of Karnovsky's primary fixative (Karnovsky 1965) consisting of 2\% glutaraldehyde, 2\% paraformaldehyde, $1.52 \% \mathrm{NaOH}$, and $1.2 \mathrm{~g} \mathrm{~d}$-glucose, dissolved in $2.25 \%$ sodium hydrogen phosphate buffer (pH 7.4). Specimens were subsequently rinsed in three changes of buffer and post-fixed for $2 \mathrm{~h}$ in $1 \% \mathrm{OsO}_{4}$ solution in $2.25 \%$ sodium hydrogen phosphate buffer ( $\mathrm{pH}$ 7.4) at room temperature, dehydrated through a graded series of ethanol, and embedded in epoxy resin (Araldite; Fluka).

One specimen was serially sectioned alternating between 16 semithin Sects. $(0.5 \mu \mathrm{m})$ and approximately 25 ultrathin Sects. $(60 \mathrm{~nm})$, another specimen was serially sectioned completely for transmission electron microscopy microscopy $(60 \mathrm{~nm})$. Sectioning was performed on a Leica Ultracut S. Semithin sections were stained using $1 \%$ toluidine blue in a solution of $1 \%$ sodium tetraborate (borax). Ultrathin sections were stained with $2 \%$ uranylacetate and $2.5 \%$ lead citrate in an automatic stainer (courtesy of Dr. Björn Quast, Universität Bonn and Dr. Alexander Gruhl, MPI Bremen).

Stained ultrathin sections were examined under a Zeiss EM9 transmission electron microscope, operated at $50 \mathrm{kV}$.

Data of the third specimen, used for the digital 3D-reconstructions, were kindly provided by Prof. Hiroki Nishida (Department of Biological Sciences, Graduate School of Science, Osaka University). These data were compiled using serial block face scanning electron microscopy. For further details see Nishida et al. (2021). The resulting image stacks were used for segmentation and 3D-reconstruction using the Amira software package (version 6.4.0). 


\section{Results}

\section{General anatomy of the pericardium and heart}

The pericardium is a fluid-filled, sac-like compartment that is continuously lined by epithelial cells. Thus, the pericardium is a true coelom. It is situated within the hemocoel of the trunk and anteriorly wedged between the stomach lobes at the base of the tail and more posteriorly bordered by the gonad and ventrally by the epidermis (Fig. 1). The pericardium in a juvenile specimen $10 \mathrm{~h}$ after fertilization measures approximately $140 \mu \mathrm{m}$ in length and is laterally compressed, so the width measures merely about 30-40 $\mu \mathrm{m}$ (Fig. 1). In height the pericardium reaches approximately $80 \mu \mathrm{m}$. It is slightly pointed anteriorly, while rounded at the posterior end. A dorsal view reveals that the flat, sac-like pericardium is somewhat spoon-shaped with a concave side towards the left lobe of the stomach and the convex facet towards the right stomach lobe.

A distinct heart is not present in Oikopleura dioica. Usually, the heart houses the hemocoelic fluid or blood and is the central site of propulsion of this fluid. In most invertebrates therefore, the heart is a distinct vessel surrounded by a coelomic compartment that on its extracellular side contains the hemocoelic fluid or blood. While in $O$. dioica the coelomic compartment, i.e., the pericardium, that agitates the hemocoelic fluid, exists, no distinct vessel can be discerned (Fig. 1a). On the left side of the pericardium, where the pericardial epithelium is made up of epithelial myocardial cells, several more or less shallow folds are seen running longitudinally along the pericardium.

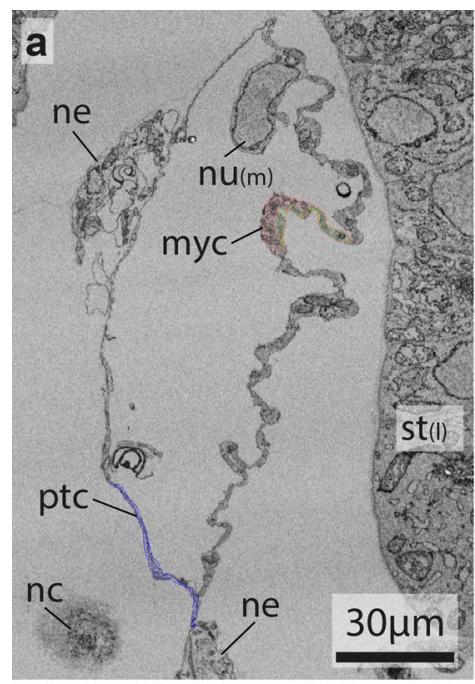

C

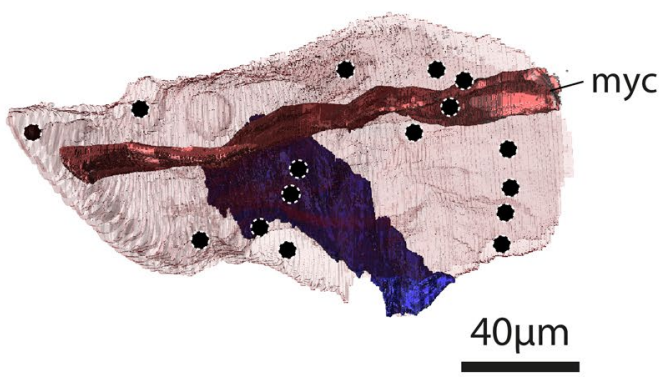

d



Fig. 1 General anatomy of the pericardium $(p c)$ of Oikopleura dioica. a Exemplary image from the series of serial block face scanning electron micrographs showing a cross section through the pericardium of $O$. dioica with a selected myocardial cell $(m y c)$ and the peritoneal cell (ptc) labeled by colors. myc-light red, ptc-blue. (b) Digital 3D-reconstruction of the trunk and parts of the tail of a juvenile of $O$. dioica seen from the left. Organ systems transparent with exception of the pericardium. c-e Digital 3D-reconstruction of the pericardium with the two cells highlighted in (a) reconstructed in more detail. Position of nuclei of all cells in the pericardium with exception of the two cells reconstructed in detail indicated by black spheres. c Pericardium seen from left side, anterior to left of image (all nuclei highlighted by dashed white circles for visibility). d Pericardium seen from dorsal, anterior to left of image. e Pericardium seen from anterior, left side of pericardium is right in the image. an anus, $b r$ brain, $n u_{(m)}$ nucleus of myocardial cell, $n c$ tip of notochord, ne nerve, oe esophagus, $p h$ pharynx, $s t_{(l)}$ left stomach lobe, $t a$ tail 


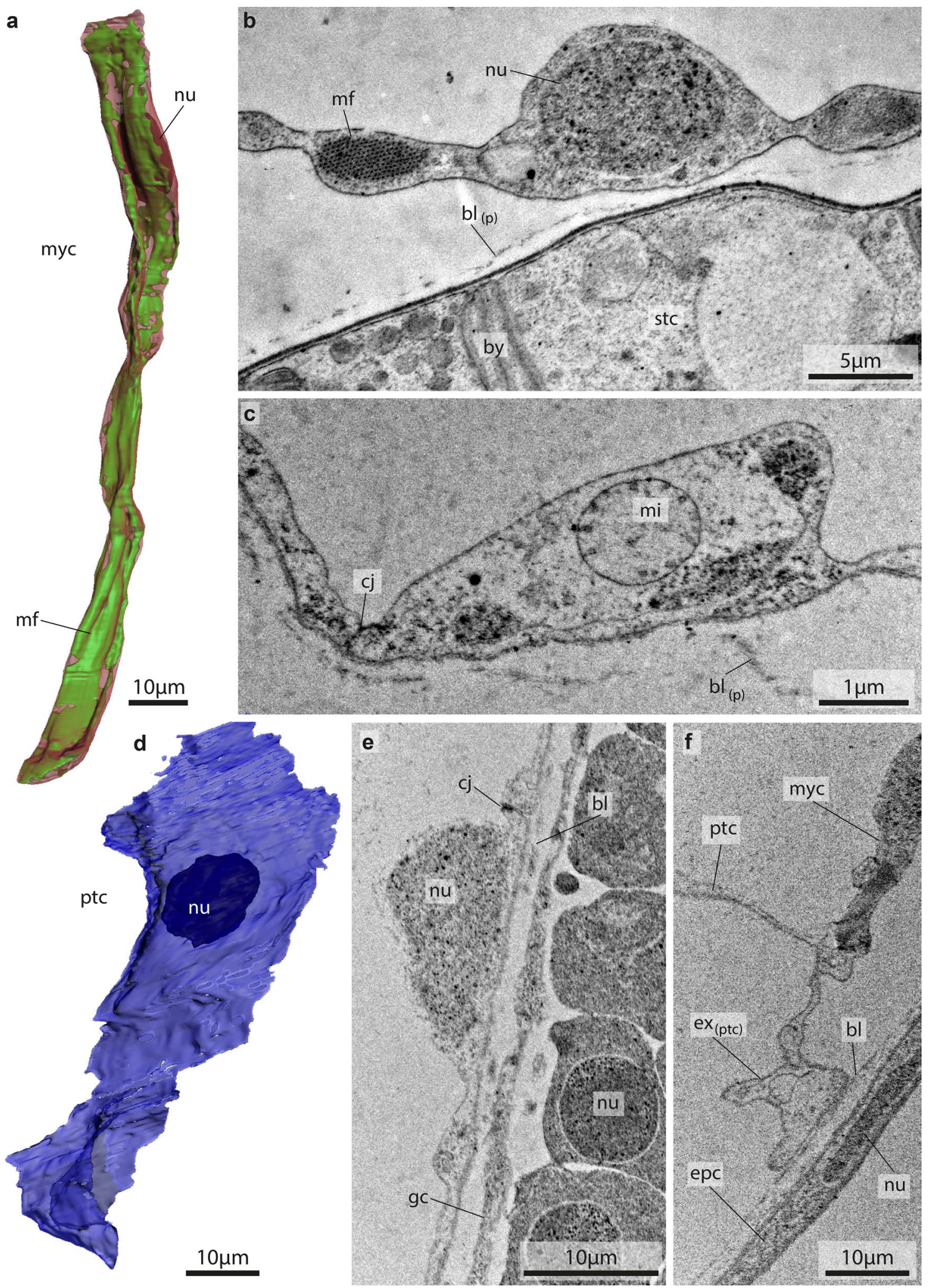

\section{The pericardial cells-general appearance}

The pericardium is completely lined by a single layer of 16 epithelial cells in total (Fig. 1a). The cells rest on a distinct basal lamina that measures only $20-50 \mathrm{~nm}$ and is of a floccular appearance (Figs. 2, 3, 4). Occasionally, the basal lamina beneath pericardial cells appears to consist of fibers (Fig. 4c). All pericardial cells are flat and therefore appear 
४Fig. 2 Details of myocardial (myc) and peritoneal (ptc) pericardial cells in Oikopleura dioica. a 3D-reconstruction of the myocardial cell shown in Fig. 1. Cell membrane: transparent red; myofibrilla $(m f)$ : green; nucleus $(n u)$ : dark pink. b Transmission electron micrograph of a myocardial cell next to left stomach lobe in perinuclear region. c Transmission electron micrograph of a myocardial at cell periphery showing cell junction $(\mathrm{cj})$ and mitochondrium $(\mathrm{mi})$. d 3D-reconstruction of the peritoneal cell shown in Fig. 1. Cell membrane-transparent blue, nucleus $(n u)$ - dark blue. e Transmission electron micrograph of peritoneal cell showing nucleus and cell junction. $\mathbf{f}$ Transmission electron micrograph at ventral border of pericardium. Note the projection of a cell with similar appearance to peritoneal cell extending to the ventro-lateral epidermis. $b l_{(p)}$ basal lamina (around pericardium), by basal labyrinth, epc epidermal cell, $e x_{(p t c)}$ projection (of peritoneal cell), $g c$ coelomic lining of gonad, stc stomach cell

thin in sections. The cells are connected to their neighboring cells via continuous, belt-like cell junctions (Figs. 2e, 3a). Apically, the pericardial cells are in contact with the coelomic fluid inside the pericardium. No apical differentiations were observed. There are two distinct different type of cells that make up the pericardium. These are the myocardial cells and the peritoneal pericardial cells (Figs. 2, 3, 4).

\section{Ultrastructure of the myocardial cells}

The six epithelial myocardial cells are elongated cells that measure approximately $150 \mu \mathrm{m}$ in length and only around $12 \mu \mathrm{m}$ in width (Fig. 2a-c). Over the most part the cells are rather flat, measuring some $2 \mu \mathrm{m}$ in height. Only, at the vicinity of the nucleus this height increases to around 5-6 $\mu \mathrm{m}$ (Figs. 2b, 3b). The myocardial cells constitute the left, concave side of the pericardium.

The myocardial cells contain a single nucleus, numerous mitochondria, and several (2-4) myofibrillae. The myofibrillae are oriented along the longitudinal axis of the myocardial cells. In cross section, the myofibrillae measure around $2 \mu \mathrm{m}$ in diameter and feature a regular arrangement of myosin fibers (Fig. 3). Unfortunately, we did not prepare longitudinal sections, but the bending of the concavity of the pericardium allowed us to document oblique sections of the myocardial cells. In these oblique sections, we could document profiles of a cross striation pattern with clearly discernible A-band (myosin and actin fibers), I-band (actin fibers), and the dark Z-disc separating sarcomeres (Fig. 3c, e). The mitochondria appear oval to round in cross section. They are of approximately $1.5 \mu \mathrm{m}$ diameter and feature tubular sectional aspects of the inner mitochondrial membranes (Fig. 3). The single nucleus is round with a diameter of around $5 \mu \mathrm{m}$ (Figs. 2b, 3b). The apical cell membrane does not feature modifications. At the cell junctions connecting neighboring myocardial cells the cell membranes appear electron darker. The membranes of the neighboring cells are apically closely apposed-less than $10 \mathrm{~nm}$ apart—and the intercellular cleft is filled with electron dark material (Fig. 3a, d, f). On the respective intracellular sides of the cell junctions electron denser plaques of about $50 \mathrm{~nm}$ by $120 \mathrm{~nm}$ are found. In these plaques some denser striation, emanating from the membrane are seen. A short distance (ca. $60 \mathrm{~nm}$ ) more basally a darker density in both membranes is found with some darker striation connecting the membranes and being perpendicular in orientation to the membrane (Fig. 3d). Here, the two cells are 15-20 nm apart.

\section{Ultrastructure of the peritoneal pericardial cells}

The ten peritoneal pericardial cells are extremely flattened epithelial cells, that measure approximately $100 \mu \mathrm{m}$ in length, about $40 \mu \mathrm{m}$ in width, and only around $0.2 \mu \mathrm{m}$ in height (Fig. 2D). The height only changes around the nucleus, which is round and has a diameter of about $3 \mu \mathrm{m}$ (Fig. 2e). These peritoneal cells possess a clear cytosol, few mitochondria and few organelles. Neighboring cells are connected by electron dense cell junctions (Fig. 2e). One of the pericardial cells, situated at the ventral border between peritoneal cells and myocardial cells, is similar to the peritoneal cells but has a slightly different shape (Fig. 2f). While the cytoplasm appears comparable to the remaining peritoneal cells, this specific cell has a projection that connects the pericardium to the basal lamina beneath the latero-ventral epidermis.

\section{Organization of body cavity and basal lamina}

The body cavity of $O$. dioica appears quite uniformly clear in electron microscopic aspect, with little signs of floccular precipitations (Figs. 1, 2, 3, 4; especially Fig. 4). The basal lamina beneath the epithelially organized cells, on the other hand, appears as a continuous line of floccular precipitation of medium electron density, constituting a sheet-like basal lamina. The basal lamina underlying the epidermis (Fig. 2f) is approximately $30 \mathrm{~nm}$ thick and closely follows the basal sides of the epidermal cells. The basal lamina underneath the pericardium (Figs. 2b, c, e, 3a, b, c, e, f, 4) is between 30 and $70 \mathrm{~nm}$ thick and pericardial cells do not follow the basal lamina closely, leaving a cleft-like space. The pericardial basal lamina is loosely organized and occasionally shows short fibers (Figs. 3b, 4c). The basal lamina underneath the stomach is again directly situated underneath the cell membranes of the basal sides of the stomach cells (Figs. 2b, 4a, b). It is more uniformly around $30 \mathrm{~nm}$ in thickness and electron darker than the basal laminae described before.

Sheets, resembling the basal lamina of the pericardium cross the larger spaces of the body cavity and are connected to the pericardial basal lamina (Fig. 4a). 



Fig. 3 Ultrastructural details of myocardial cells in the pericardium of Oikopleura dioica. a Note several myofibrillae $(\mathrm{mf})$ in a single myocardial cell. b The round nucleus is clearly seen. $\mathbf{c}$ Each myofibrilla is associated with mitochondria $(\mathrm{mi})$. d Detail of cell junction (magnification of area in (f)). e Cross striation pattern in a slightly obliquely sectioned myofibril shows a-band with myosin filaments (my), i-band with actin filaments (ac), and the dark z-band within the i-band. $\mathbf{f}$ Cross section of myofibrilla at higher magnification reveals the regular arrangement of myosin and actin filaments. Dotted square indicates magnified area in (d). $b l$ basal lamina, $c j$ cell junction, $\mathrm{cm}$ cell membrane, $n u$ nucelus, stc stomach cell, $z$ z-line 

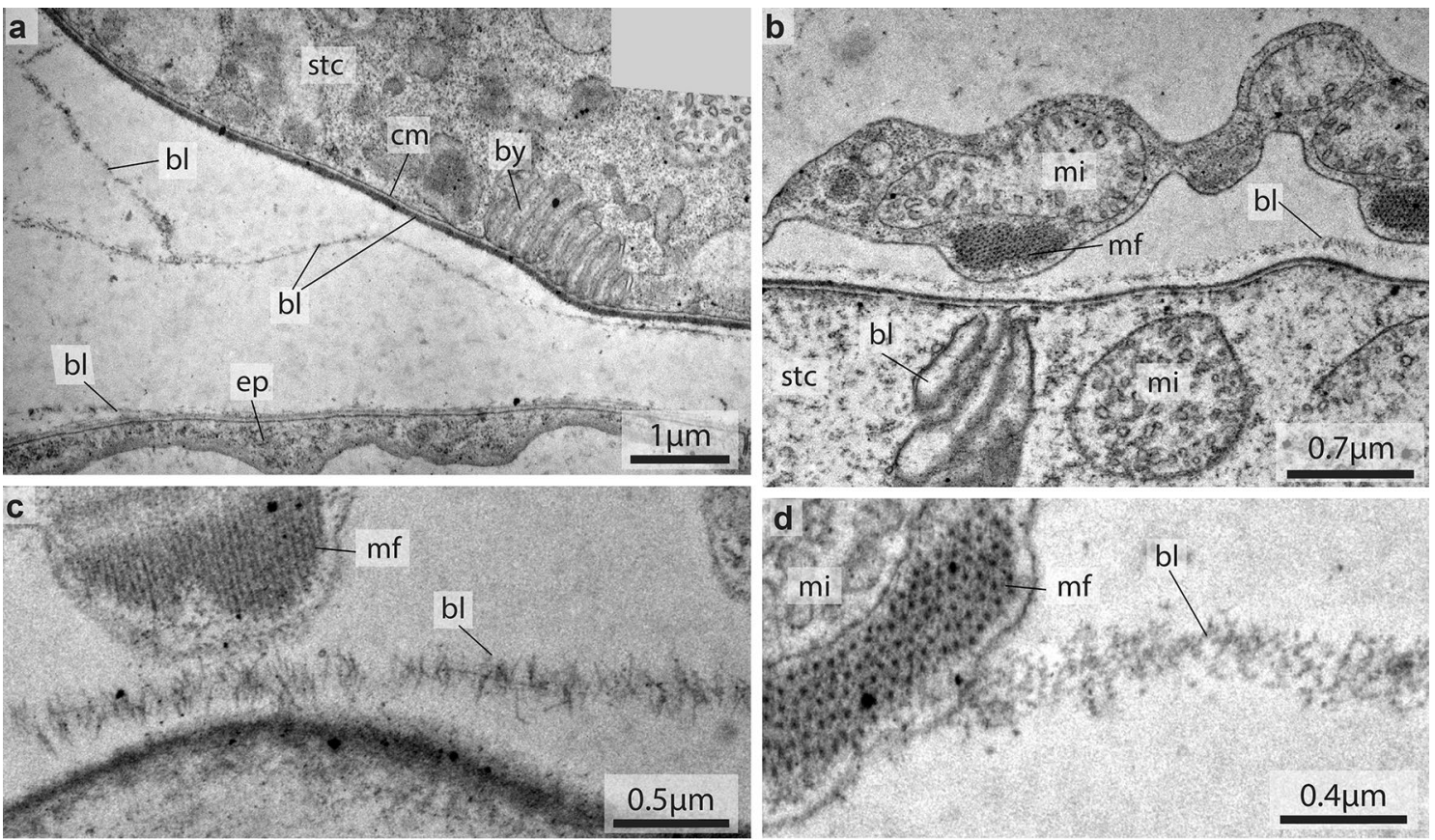

Fig. 4 Ultrastructure of the basal lamina $(b l)$ in different parts of the body of Oikopleura dioica. a The two sheets of bl of epidermis (ep) and stomach cells (stc) are clearly visible. Note that the sectioned blsheet underlying the stc bifurcates at the left side of the image and that a dark, granulated bl line underlies the basal cell membrane $(\mathrm{cm})$ of the stc. $\mathbf{b}$ The bl surrounding the pericardium has a floccular

\section{Discussion}

Due to its phylogenetic position within Tunicata (e.g., Delsuc et al. 2018; Kocot et al. 2018; Braun et al. 2020) and its peculiar life history with extremely accelerated development and short life cycle (e.g., Stach et al. 2008; Bouquet et al. 2009), Oikopleura dioica among appendicularians has been developed into a model organism for modern sophisticated research (e.g., Danks et al. 2013; Ferrández-Roldán et al. 2021). The phylogenetic position of course is a prerequisite to elucidate evolution, but a final goal in evolutionary research is a more complete understanding of the evolutionary changes that occur along the lineages. Such evolutionary changes naturally include molecular developmental changes as well as changes in life-history, ecology, and last but not least also morphological changes. In order to elucidate morphological transformations in evolution, a detailed knowledge of morphological traits is desirable and model organisms are among other reasons chosen because much of their morphology is known. Because the ultrastructural morphology of the pericardium of this important model organism has been hardly analyzed, we filled this gap with the aim to draw functional and evolutionary conclusions.

Based on ultrastructural observations, we could unequivocally demonstrate that two cell types are present in the appearance of medium electron density. Note again the dark, granulated bl underlying the basal cell membrane of the stc. c At higher magnification, short fibers are visible in this part of the bl surrounding the pericardium. $\mathbf{d}$ In other places the bl surrounding the pericardium appears more floccular. by basal labyrinth, $m f$ myofibrilla, $m i$ mitochondria

epithelial lining of the pericardium: six myocardial cells on the left side of the pericardium and ten peritoneal cells on its right. Although these had not been characterized in detail for $O$. dioica before, it was not an unexpected finding, because Onuma et al (2017) and Nishida et al. (2021) had already noticed a difference in thickness between the left and right sides of the pericardial epithelium. In addition, Savelieva and Temereva (2020) described the ultrastructure of myocardial and peritoneal cells for the closely related species O. gracilis. Two similarly ultrastructurally different types of pericardial cells are also present in ascidans (see below) and can, therefore, plausibly be inferred to be homologous to the ones found in appendicularians. We, therefore, expect two cell types, myocardial and peritoneal cells, to be more wide-spread among appendicularians and indeed constitute the plesiomorphic condition of the pericardium within Appendicularia. We also observed a specialized peritoneal cell in the posterior part of the pericardium. This cell was attached to the basal membrane of the epidermis via a cellular projection. Such a cell had not been described before. Unfortunately, we were unable to characterize this specialized peritoneal cell further and additional investigations are necessary to substantiate this finding. Functional, such a cell would clearly serve as an anchoring cell, holding the pericardium securely in position. 
A tubular, blood-filled heart is missing in $O$. dioica, yet the function of the pericardium seems to be in agitating the hemocoelic fluid. The driving force of this agitation are the six myocardial cells situated on the left, concave side of the pericardium. The overall shape of the pericardium would facilitate this function as well. On contraction of the sarcomeres in the longitudinally oriented myofibrillae within the myocardial cells, the fluid filled space within the concavity of the right side of the pericardium becomes smaller. Upon relaxation a-presumably elastic-rebound would draw in hemocoelic fluid. The longitudinal folds along the right side of the pericardium might support this fluid dynamics, possibly resulting in an increase of flow velocity in the narrow space between the left side of the pericardium and the left lobe of the stomach.

Under functional considerations, the basal lamina-like structures in the extracellular matrix of the hemocoel are significant as well. These structures were for the first time observed in appendicularians by Savelieva and Temereva (2020) in the wide hemocoelic space of the tail in Oikopleura gracilis. We also found these structures spanning the hemocoel in various places in $O$. dioica. We suspect that they are sheet-like, because they were found regularly and were traceable over some distance in consecutive sections. However, because we did not reconstruct 3D-details of these structures, this conclusion is also in need of further analyses. We suspect that these basal lamina-like structures are the main structures channeling and directing fluid motion in the hemocoel. As Savel'eva et al. (2013) and Savelieva and Temereva (2020) have pointed out for $O$. gracilis, the hemocoelic cavity in $O$. gracilis is rather unbalanced, with a smaller volume in the trunk and a larger volume in the tail, although no formal 3D-reconstruction had been executed by these authors. This imbalance would make it hard to understand, how the hemocoelic fluid in the tail could be included in the general fluid motion of the trunk, driven by the pericardium. In this regard, the position of the pericardium at the junction of the trunk and tail is probably of significance and the basal lamina-like structures could serve a pivotal role in directing fluid motion and integrate fluid motion of tail and trunk compartments.

A pulsatile pericardial coelomic compartment is present in invertebrate deuterostomes, e.g., in echinoderms (e.g., Narasimhamurti 1932; Ruppert and Balser 1986), enteropneusts (e.g., Benito and Pardos 1997; Kaul-Strehlow and Stach 2011; Gonzalez et al. 2018), pterobranchs (e.g., Dilly et al. 1986; Merker et al. 2014), and invertebrate chordates (see review in Stach 2008). The similarities in position and functional context of the major ventral vessel and the pulsatile coelomic compartment in cephalochordates (e.g., Rähr 1979; Stach 1998) and ascidians (e.g., Corly 1995; Burighel and Cloney 1997; Konrad 2016) support the hypothesis that these structures are homologous to the heart in craniates (e.g., Hirakow 1989; Stach 2008; Xavier-Neto et al. 2010; see also Fig. 5). This hypothesis has been supported by additional similarities in gene regulatory networks during development as elucidated in the model organism Ciona robusta compared to the more intensely studied craniates (e.g., Davidson 2007; Anderson and Christiaen 2016).

In ascidians, the cytological situation seems more easily comparable to the situation in developing craniates (e.g., Hirakow 1989; see also Fig. 5). The myocytes of the pericardial sac in ascidians are similar in organization and position to the myocardial cells developing from the splanchnic sheet of the lateral plate. The peritoneal cells of the pericardial compartment in ascidians corresponds to the somatic layer of the lateral plate that develop into the epicardial cell layer in craniates (e.g., Lemanski 1973; Fransen and Lemanski 1990; Onimaru et al. 2011). In craniates, more precisely since the stem lineage of Craniota, an additional epithelial cell layer lines the blood vessels and thus the heart as well. This additional epithelial cell layer is the endothelium (e.g., Mickoleit 2004; Monahan-Earley et al. 2013), and it constitutes an apomorphic trait of craniates. Thus, within the heart-pericardial complex we can distinguish several traits that evolved independently.
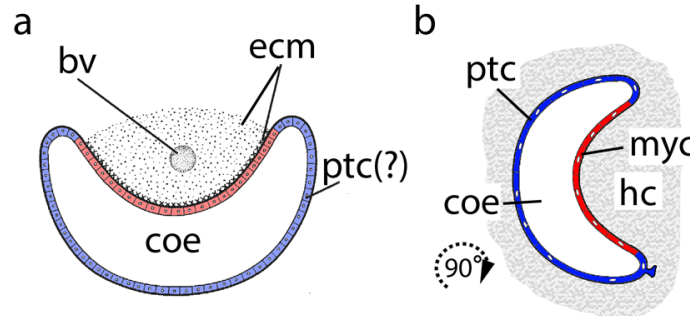

Fig. 5 Schematic cross-sections through the developing heart in the four higher chordate taxa as seen from anterior end. a Branchiostoma lanceolatum, after Stach (1998); b Oikopleura dioica (present study; arrow indicates inferred rotation through 90 degrees to the left of the animal); c Ciona intestinalis, after Oliphant and Cavey (1972); d not
C



d

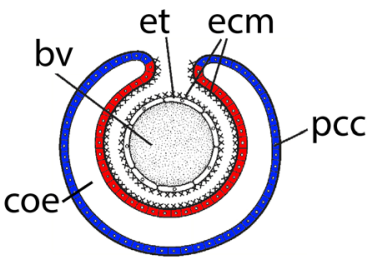

further specified craniate, after Hirakow (1989). $b v$ blood vessel, coe pericardial coelom, ecm extracellular material, et endothelium, $h c$ hemocoel, $m y c$ myocardial cells, $p t c$ peritoneal cells, $p c c$ pericardial cells 
The presence of two different cell types-peritoneal cells and myocardial cells-is clearly documented in tunicates (ascidians [e.g., Oliphant and Cloney 1972, Burighel and Cloney 1979) and appendicularians Savelieva and Temereva 2020, present study)] and craniates (e.g., Lemanski 1973; Fransen and Lemanski 1990; Onimaru et al. 2011). The organization in cephalochordates (see Fig. 5a) is not clear, but Stach $(1998,2000)$ reported the presence of two cell types in the ventral coelom that propels blood flow in early developmental stages of cephalochordates at the exact position of the craniate heart (Stach 1998). However, this author did not investigate the detailed arrangement of these cells. But already in pterobranchs and enteropneusts these two cell types can clearly be distinguished in the splanchnic and somatic portions of the pulsatile protocoel (e.g., Benito and Pardos 1997; KaulStrehlow and Stach 2011; Merker et al. 2014). This comparative overview leads to the conclusion that the presence of two functionally differentiated cell types in the coelomic compartment that serves as main driving force of the blood circulation is a plesiomorphic trait within Chordata, possibly already present in the last common ancestor of Deuterostomia.

It is noteworthy that the pericardium in craniates does not correlate in a one to one correspondence to the pericardium in invertebrate chordates. In mature craniates, the myocardium is separated from the pericardium. Based on studies of the development of amphibians and fishes, Hirakow (1989) suggested that myocardial cells and peritoneal cells separate from a rudimentary pericardium during ontogeny (Fig. 5d). Whereas the latter cells constitute the pericardium in the mature animal, the former intermingle with endothelial cells and constitute the myocardium. According to this hypothesis, the pericardium in craniates therefore comprises only a part of the cell population originally present in the pericardium of non-craniate chordates: the cells we have termed peritoneal pericardial cells.

The juxtaposition of schematic representations of cross sections through heart-pericardial complexes of chordate representatives in Fig. 5, visualizes another trait associated with this complex the orientation of the mirror-image symmetry axis of the pericardium compared to the main body axis. While these two axes coincide in cephalochordates, ascidians, and craniates, the former is tilted by 90 degrees to the left in $O$. dioica. Thus, in this species the heart is oriented the same way as the tail, which rotates during early development (Stach et al. 2008). The rotation of the axis of the appendicularian heart is another apomorphic trait of appendicularians. Moreover, this morphological observation confirms the hypothesis of Davidson et al. (2005) that heart cell specification and morphogenetic movements of developing heart cells can be decoupled.
Acknowledgements We express our deep gratitude to Prof. Hiroki Nishida (Osaka University, Osaka, Japan) for generously sharing his SBF-SEM data with us. This research was supported by a Grant from the GIF, the German-Israeli Foundation for Scientific Research and Development (Grant no. I-1454-203.13/2018 to TS and DH).

Funding Open Access funding enabled and organized by Projekt DEAL.

Open Access This article is licensed under a Creative Commons Attribution 4.0 International License, which permits use, sharing, adaptation, distribution and reproduction in any medium or format, as long as you give appropriate credit to the original author(s) and the source, provide a link to the Creative Commons licence, and indicate if changes were made. The images or other third party material in this article are included in the article's Creative Commons licence, unless indicated otherwise in a credit line to the material. If material is not included in the article's Creative Commons licence and your intended use is not permitted by statutory regulation or exceeds the permitted use, you will need to obtain permission directly from the copyright holder. To view a copy of this licence, visit http://creativecommons.org/licenses/by/4.0/.

\section{References}

Anderson HE, Christiaen L (2016) Ciona as a simple chordate model for heart development and regeneration. J Cardiovasc Dev Dis 3:1-25. https://doi.org/10.3390/jcdd3030025

Benito J, Pardos F (1997) Hemichordata. In: Harrison FW, Ruppert EE (eds) Microscopic anatomy of invertebrates. Wiley-Liss, New York, pp 15-101

Bouquet J-M, Spriet E, Troedesson C, Ottera H, Chourrout D, Thompson EM (2009) Culture optimization for the emergent zooplanktonic model organism Oikopleura dioica. J Plank Res 31:359-370. https://doi.org/10.3390/jcdd3030025

Braun K, Leubner F, Stach T (2020) Phylogenetic analysis of phenotypic characters of Tunicata supports basal Appendicularia and monophyletic Ascidiacea. Cladistics 36:259-300. https://doi.org/ 10.1111/cla.12405

Burighel P, Cloney RA (1997) Urochordata: Ascidiacea. In: Harrison FW, Ruppert EE (eds) Microscopic anatomy of invertebrates, vol 15. Wiley-Liss, New York, pp 221-337

Burighel P, Lane NJ, Martinucci GB, Fenaux R, Dallai R (1989) Junctional diversity in two regions of the epidermis of Oikopleura dioica (Tunicata, Larvacea). Cell Tissue Res 257:529-535. https:// doi.org/10.1007/BF00221462

Cañestro C, Bassham S, Postlethwait J (2005) Development of the central nervous system in the larvacean Oikopleura dioica and the evolution of the chordate brain. Dev Biol 15:298-315. https://doi. org/10.1016/j.ydbio.2005.06.039

Corly LS (1995) The vascular anatomy of Ascidia interrupta (Urochordata, Ascidiacea) in relation to heart beat reversal. Master thesis, Clemson University, South Carolina

Danks G, Campsteijn C, Parida M, Butcher S, Doddapaneni H, Fu B, Petrin R, Metpally R, Lenhard B, Wincker P, Chourrout D, Thompson EM, Manak JR (2013) OikoBase: a genomics and developmental transcriptomics resource for the urochordate Oikopleura dioica. Nucleic Acids Res 41:D845-D853. https://doi.org/ 10.1093/nar/gks1159

Davidson B (2007) Ciona intestinalis as a model for cardiac development. Semin Cell Dev Biol 18:16-26. https://doi.org/10.1016/j. semcdb.2006.12.007 
Davidson B, Shi W, Levine M (2005) Uncoupling heart cell specification and migration in the simple chordate Ciona intestinalis. Development 132:4811-4818. https://doi.org/10.1242/dev.02051

Delsuc F, Brinkmann H, Chourrout D, Philippe H (2006) Tunicates and not cephalochordates are the closest living relatives of vertebrates. Nature 439:965-968. https://doi.org/10.1038/nature04336

Delsuc F, Philippe H, Tsagkogeorga G, Simion P, TilakTuronLópezLegentilPietteLemaireDouzery M-KXSJPEJP (2018) A phylogenomic framework and timescale for comparative studies of tunicates. BMC Biol 16:39. https://doi.org/10.1186/ s12915-018-0499-2

Dilly PN, Welsch U, Rehkämper G (1986) Fine structure of heart, pericardium and glomerular vessel in Cephalodiscus gracilis M'Intosh, 1882 (Pterobranchia, Hemichordata). Acta Zool 67:173-179. https://doi.org/10.1111/j.1463-6395.1986.tb00861.x

Evans HE, Christiaen L (2016) Ciona as a simple chordate model for heart development and regeneration. J Cardiovasc Dev Dis 3:25. https://doi.org/10.3390/jcdd3030025

Farrell AP (2007) Cardiovascular systems in primitive fishes. Fish Physiol 26:53-120. https://doi.org/10.1016/S1546-5098(07) 26002-9

Ferrández-Roldán A, Fabregà-Torrus M, Sánchez-Serna G, DuránBello E, Joaquín-Lluís M, Garcia-Fernàndez J, Albalat R, Cañestro C (2021) Cardiopharyngeal deconstruction and ancestral tunicate sessility. BioRxiv. https://doi.org/10.1101/2021.02. 10.430586

Fransen ME, Lemanski LF (1990) Epicardial development in the axolotl, Ambystoma mexicanum. Anat Rec 226:228-236. https:// doi.org/10.1002/ar.1092260212

Ghadam M, EbrahimzadehMousavi HA, Rahmati-Holasoo H, Shafiei S (2016) Comparative study of the circulatory system of common carp (Cyprinus carpio Linnaeus, 1758) and beluga (Huso huso Linnaeus, 1758): a corrosion cast study. J Appl Ichthyol 32:11-17. https://doi.org/10.1111/jai.12966

Glover JC (2020) Oikopleura. Curr Biol 30:R1233-R1255. https:// doi.org/10.1016/j.cub.2020.07.075

Gonzalez P, Jiang JZ, Lowe CJ (2018) The development and metamorphosis of the indirect developing acorn worm Schizocardium californicum (Enteropneusta: Spengelidae). Front Zool 15:26. https://doi.org/10.1186/s12983-018-0270-0

Hirakow R (1989) Origin and differentiation of the chordate heart. In: Splechtna H, Hilgers H (eds) Trends in vertebrate morphology. Gustav Fischer Verlag, Stuttgart, pp 261-263

Holmberg K (1984) A transmission electron microscopic investigation of the sensory vesicle in the brain of Oikopleura dioica (Appendicularia). Zoomorphology 104:298-303. https://doi. org/10.1007/BF00312011

Holmberg K (1986) The neural connection between the Langerhans receptor cells and the central nervous system in Oikopleura dioica (Appendicularia). Zoomorphology 106:31-34. https:// doi.org/10.1007/BF00311944

Hoshino Z-I (1969) On the development of the circulatory system of the young ascidian, Ciona robusta. Publ Seto Mar Biol Lab 17:7-17. https://doi.org/10.5134/175569

Karnovsky MJ (1965) A formaldehyde-glutaraldehyde fixative of high osmolality for use in electron microscopy. J Cell Biol 27:137

Kaul-Strehlow S, Stach T (2011) The pericardium in the deuterostome Saccoglossus kowalevskii (Enteropneusta) develops from the ectoderm via schizocoely. Zoomorphology 130:107-120. https://doi.org/10.1007/s00435-011-0125-0

Kishi K, Hayashi M, Onuma TA, Nishida H (2017) Patterning and morphogenesis of the intricate but stereotyped oikoplastic epidermis of the appendicularian, Oikopleura dioica. Devel Biol 428:245-257. https://doi.org/10.1016/j.ydbio.2017.06.008
Kocot KM, Tassi MG, Halanych KM, Swalla BS (2018) Phylogenomics offers resolution of major tunicate relationships. Mol Phyl Evol 121:166-173. https://doi.org/10.1016/j.ympev.2018. 01.005

Kokubo N, Matsuura M, Onimaru K, Tiecke E, Kuraku S, Kuratani S, Tanaka M (2010) Mechanisms of heart development in the Japanese lamprey, Lethenteron japonicum. Evol Dev 12:34-44. https://doi.org/10.1111/j.1525-142X.2009.00389.x

Konrad MW (2016) Blood circulation in the ascidian tunicate Corella inflata (Corellidae). PeerJ 4:e2771. https://doi.org/10. 7717/peerj.277d

Lambertz M (2016) Craniota vs. Craniata: arguments towards nomenclatural consistency. J Zool Syst Evol Res 54:174-176. https://doi.org/10.1111/jzs.12126

Lankester ER (1874) On the heart of Appendicularia furcata and the development of its muscular fibres. J Cell Sci 2:274-277. https://doi.org/10.1242/jcs.s2-14.55.274

Lemanski LF (1973) Morphology of developing heart in cardiac lethal mutant Mexican axolotls, Ambystoma mexicanum. Dev Biol 33:312-333. https://doi.org/10.1016/0012-1606(73) 90140-1

Merker S, Gruhl A, Stach T (2014) Comparative anatomy of the heart-glomerulus complexof Cephalodiscus gracilis (Pterobranchia): structure, function, and phylogenetic implications. Zoomorphology 133:83-98. https://doi.org/10.1007/ s00435-013-0200-9

Mickoleit G (2004) Phylogenetische Systematik der Wirbeltiere. Verlag Dr Friedrich Pfeil, München

Monahan-Earley R, Dvorak AM, Aird WC (2013) Evolutionary origins of the blood vascular system and endothelium. J Thrombosis Haemostasis 11:46-66. https://doi.org/10.1111/jth.12253

Nakashima K, Nishino A, Hirose E (2011) Forming a tough shell via an intracellular matrix and cellular junctions in the tail epidermis of Oikopleura dioica (Chordata: Tunicata: Appendicularia). Naturwissenschaften 98:661-669. https://doi.org/10. 1007/s00114-011-0815-y

Narasimhamurti $\mathrm{N}$ (1932) The development and function of the heart and pericardium in Echinodermata. J Roy Soc B 109:471-487. https://doi.org/10.1098/rspb.1932.0007

Nishida H, Ohno N, Caicci F, Manni L (2021) 3D reconstruction of structures of hatched larva and young juvenile of the larvacean Oikopleura dioica using SBF-SEM. Sci Rep 11:4833. https:// doi.org/10.1038/s41598-021-83706-y

Oliphant LW, Cavey MJ (1972) The ascidian myocardium: sarcoplasmic reticulum and excitation-contraction coupling. Cell Tissue Res 129:395-412. https://doi.org/10.1007/BF00307296

Olsson R, Holmberg K, Lilliemarck Y (1990) Fine structure of the brain and brain nerves of Oikopleura dioica (Urochordata, Appendicularia). Zoomorphology 110:1-7. https://doi.org/10. 1007/BF01632806

Onimaru K, Shoguchi E, Kuratani S, Tanaka M (2011) Development and evolution of the lateral plate mesoderm: comparative analysis of amphioxus and lamprey with implications for the acquisition of paired fins. Dev Biol 359:124-136. https://doi. org/10.1016/j.ydbio.2011.08.003

Onuma TA, Isobe M, Nishida H (2017) Internal and external morphology of adults of the appendicularian, Oikopleura dioica: an SEM study. Cell Tissue Res 367:213-227. https://doi.org/ 10.1007/s00441-016-2524-5

Rähr H (1979) The circulatory system of amphioxus Branchiostoma lanceolatum (Pallas): a light-microscopic investigation based on intravascular injection technique. Acta Zool 60:1-18. https:// doi.org/10.1111/j.1463-6395.1979.tb00594.x

Ruppert EE, Balser EJ (1986) Nephridia in the larvae of hemichordates and echinoderms. Biol Bull 171:188-196. https://doi.org/ $10.2307 / 1541916$ 
Savel'evaTemerevaDautov AVENSS (2013) Organization of the body cavity in appendicularian (Chordata: Appendicularia) is not typical for Deuterostomian. Doklady of the Russ Acad Sci 448:490-493. https://doi.org/10.1134/S0012496613010134

Savelieva AV, Temereva EN (2020) Ultrastructure of the body cavities in juveniles and adults of the appendicularian Oikopleura gracilis (Tunicata, Chordata) suggests how the heart may have evolved in tunicates. Inv Biol 139:e12286. https://doi.org/10. $1111 /$ ivb. 12286

Stach T (1998) Coelomic cavities may function as a vascular system in amphioxus larvae. Biol Bull 195:260-263. https://doi.org/ $10.2307 / 1543137$

Stach T (2000) Microscopic anatomy of developmental stages of Branchiostoma lanceolatum (Cephalochordata, Chordata). Bonn Zool Monogr 47:1-111

Stach T (2008) Chordate phylogeny and evolution: a not so simple three- taxon problem. J Zool 276:117-141. https://doi.org/10. 1111/j.1469-7998.2008.00497.x
Stach TG (2009) Anatomy of the trunk mesoderm in tunicates: homology considerations and phylogenetic interpretation. Zoomorphology 128:97-109. https://doi.org/10.1007/ s00435-008-0076-2

Stach T, Winter J, Bouquet J-M, Chourrout D, Schnabel R (2008) Evolution of life-cycles: the embryology of a planktonic tunicate reveals traces of sessility. Proc Natl Acad Sci USA 105:7229-7234. https://doi.org/10.1073/pnas.0710196105

Publisher's Note Springer Nature remains neutral with regard to jurisdictional claims in published maps and institutional affiliations. 